DOI: https://doi.org/10.5007/1980-3532.2017n17p55

\title{
O relógio ou nós? Uma visão da invenção do tempo social na percepção político-cultural de Edward P. Thompson
}

\author{
The time or us? A view of the invention of social time in Edward \\ $P$. Thompson's political-cultural perception
}

\author{
Artur Mazzucco Fabro \\ Universidade Federal de Santa Catarina \\ Mestre em Sociologia política \\ arturfabro@gmail.com
}

\begin{abstract}
Resumo: As obras de E.P Thomspon permeiam uma diversidade de assuntos que se encaixam muito bem nas chamadas ciências sociais, entretanto, por ser um historiador, seu pensamento adquire um cunho muito proveitoso para a disciplina da História: a dita história vista de baixo. Foi a partir dessa escolha de análise, que poderia ser creditada vista a influência de Marx e do marxismo em sua vida, que o historiador inglês consegue construir uma narrativa muito rica da maneira com que os trabalhadores ingleses estavam se relacionando com o restante da sociedade onde viviam; como compartilhavam seus costumes em comum e quais eram suas peculiaridades comparadas ao restante da Europa. No meio de tantos acontecimentos em decorrência do avanço do capitalismo, o "surgimento" do tempo enquanto necessário para regular as relações de trabalho se mostrou como um terreno fértil para que se desvendem algumas características desse sistema econômico que mudou completamente a humanidade.
\end{abstract}

Palavras-chave: E.P. Thompson; Capitalismo. Tempo social. Revolução Industrial. História vista-debaixo.

\begin{abstract}
The works of E.P Thomspon permeate a diversity of subjects that fit very well in the so-called social sciences; however, being a historian, his thinking acquires a very useful mark for the discipline of History: the said history seen from below. It was from this choice of analysis that could be credited with the influence of Marx and Marxism in his life that the English historian is able to construct a very rich narrative of the way in which English workers were relating to the rest of society where They lived; How they shared their customs in common, and what their peculiarities were compared to the rest of Europe. In the midst of so many events as a result of the advance of capitalism, the "emergence" of time as necessary to regulate labor relations proved to be a fertile ground for revealing some characteristics of this economic system that completely changed humanity.
\end{abstract}

Key-words: E.P. Thompson; Capitalism. Social time. Industrial Revolution. View-low history.

Originais recebidos em: 20/08/2017

Aceito para publicação em: 15/06/2018

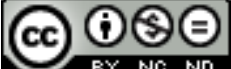
Comercial-Vedada a criação de obras derivadas 3.0 Unported License

Revista Em Debate (UFSC), Florianópolis, volume 17, p. 55-69, 2017. ISSNe 1980-3532 


\section{Introdução}

Poucos são os intelectuais que possuem uma trajetória de vida pessoal que se assemelhe com suas produções acadêmicas, ou seja, que haja uma espécie de conexão entre sua prática do dia-a-dia com a teoria produzida para a vida na Universidade. A carreira de E.P. Thompson é singular em vários sentidos, todavia, é inegável que seus afazeres fora dos centros universitários assumam um lugar de destaque em sua biografia.

Com a explosão da Segunda Guerra Mundial, Thompson luta na Itália contra o fascismo de Mussolini, sendo que logo após funda, com outros grandes intelectuais marxianos - Eric Hobbsbawn e Perry Anderson eram alguns dos nomes -, uns grupos de estudos aonde viriam a refletir exaustivamente o legado de Marx, adicionando a isso sua filiação ao Partido Comunista Britânico, temos no autor um engajamento político que modificou sua vida. $\mathrm{O}$ anseio de Thompson na Universidade de Leeds, uma das poucas ao qual se filiou, se concentrou em ministrar aulas não acadêmicas para trabalhadores ${ }^{1}$, repassando sua visão histórico-materialista do mundo a quem interessasse acompanhalo em suas críticas aos sistemas político e social do capitalismo moderno. Por esses motivos e muitos outros que não caberiam neste ensaio, os trabalhos de Thompson devem ser apreciados levando em conta sua história de vida, se não a análise de suas palavras não irá fazer sentido algum.

De forma indelével, E. P. Thompson foi um dos maiores historiadores da segunda metade do século XX. A sua ampla e polêmica produção historiográfica e a sua intensa militância política espraiaram as suas ideias e a sua influência entre os(as) historiadores(as) e cientistas sociais, notadamente aqueles(as) vinculados(as) à tradição marxista heterodoxa. (MULLER \& MUNHOZ, 2010, p.1).

Iniciando nosso raciocínio sobre a "criação" do tempo, Thompson separa uma sessão de seu Costumes em comum, que fora lançado em 1991, para discutir essa questão de notável importância. Um dos pontos principais do nascimento do relógio se encontra na disciplina de trabalho que ele acarreta. $\mathrm{O}$ argumento de Thompson se liga muito a essa disciplina, pois, anteriormente, como ele demonstra não só em Costumes

\footnotetext{
1 "Thompson nunca se estabeleceu no mundo universitário e acadêmico. Atuou como professor e pesquisador associado a uma universidade em poucas ocasiões. Permaneceu um livre pesquisador, contudo, a depender de bolsas, patrocínios ou eventuais financiamentos para os seus estudos." (MULLER \& MUNHOZ, 2010, p.2).

Revista Em Debate (UFSC), Florianópolis, volume 17, p. 55-69, 2017. ISSNe 1980-3532
} 
em comum $^{2}$, a classe trabalhadora inglesa não compartilhava dos mesmos costumes e cultura que a burguesia e a nobreza dividiam entre si, muito pelo contrário, havia uma resistência por parte desses indivíduos em se adequar forçosamente a algumas mudanças, tendo o relógio sido uma dessas.

A difusão dessa nova forma de disciplinar o trabalhador veio, então, com uma série de protestos. Se levarmos em conta, como o autor, que os relógios começaram a popularizar-se em meados do século XIV, o impacto que essa invenção teve foi crucial para que a industrialização se firmasse. Com uma rotina de trabalho comandada por ponteiros que definem exatamente o quanto trabalhar, a dinâmica da disciplina expõe um de seus ápices, já que Thompson oferece diversos exemplos de sociedades "primitivas" que sempre se guiaram pelos eventos da natureza, mas as inovações de uma economia de mercado não podem esperar que o trabalhador acorde com o amanhecer do Sol, o mercado não pode correr esse risco.

\begin{abstract}
Essa medição incorpora uma relação simples. Aqueles que são contratados experenciam uma distinção entre o tempo do empregador e o seu "próprio" tempo. E o empregador deve usar o tempo de sua mão-de-obra e cuidar para que não seja desperdiçado: o que predomina não é a tarefa, mas o valor do tempo quando reduzido a dinheiro. $\mathrm{O}$ tempo é agora moeda: ninguém passa o tempo, e sim o gasta. (THOMPSON, 1998, p.272).
\end{abstract}

As referências a Marx se tornam óbvias nessa passagem. Além da disciplina para com o trabalhador, o tempo adquire um status de valor no capitalismo, um valor que foi inventado e transformado em moeda. Toda mão-de-obra contratada ao custo de algum dinheiro traz consigo um relógio que serve como depósito: quanto mais se gasta as horas, mais se ganha dinheiro. Essas complicações não só transformaram as relações de trabalho, como também foram essenciais para mudanças no "tempo social" dos homens e mulheres. Thompson anexa em sua argumentação um leque de poemas, discursos e leis que faziam menção à, por exemplo, homens que doavam/vendiam suas terras para a construção de relógios públicos e/ou sinos em igrejas, com a intenção de que as pessoas daquelas comunidades soubessem qual seria a hora do toque de recolher ou da missa, atribuindo cada vez mais à contagem do tempo um sentido de reclusão para alguma atividade.

\footnotetext{
${ }^{2}$ A maioria das publicações de Thompson lida com o conflito entre política, cultura, economia, costumes etc. entre as classes. Citando algumas: A formação da classe operária inglesa (primeiro volume publicado em 1963); A miséria da teoria e Senhores e caçadores.
}

Revista Em Debate (UFSC), Florianópolis, volume 17, p. 55-69, 2017. ISSNe 1980-3532 
Assim sendo, a história social de Thompson não se limita ao que comumente se rotula como sendo uma história vista de baixo, e essa afirmação serve para engrandecer ainda mais o autor, uma vez que, apesar de marxiano, o jeito que Thompson faz História não se restringe a uma ou outra corrente de interpretação, podemos encontrar uma variedade de estratégias que ele utiliza quando analisa acontecimentos de acordo com o materialismo histórico dialético, por exemplo, ou mesmo se utilizando de uma história das ideias para oferecer ao leitor um estudo mais completo acerca daquilo que ele está abordando. O presente ensaio tem por intenção contribuir singelamente (mas também criticamente) com as discussões relacionadas a algumas obras de Thompson e, mais enfaticamente, ao tema do tempo e da disciplina no capitalismo.

\section{A metaformose no tempo que mudou a relação com o trabalho}

Com a invenção e, principalmente, popularização dos relógios iniciando no século XIV, - lembrando que a utilização dos relógios de Sol era bem anterior - é necessário que se faça uma regressão na história para que essas mudanças sejam entendidas, e é isso que Thompson, como um bom historiador, o faz. O autor comenta que nos povos "primitivos" a medição do tempo era aliada às atividades domésticas e ao ciclo de trabalho das famílias. Utilizando de um dos estudos do antropólogo EvansPritchard, Thompson mobiliza que os nuer - tribo localizada no Sudão - contavam seu tempo de acordo com as atividades relacionadas à criação do gado, obtendo essa sucessão de tarefas a função de determinar o tempo gasto para o trabalho, de forma simples e não muito calculada.

Já com outra tribo, os nandi, que viviam no Quênia, observa-se uma evolução na noção da contagem do tempo, sendo que a cada meia hora do dia os membros dessa tribo lançam alguma atividade: “[...] às 5 h30 da manhã os bois já foram para o pasto, às 6h as ovelhas foram soltas, às $6 \mathrm{~h} 30 \mathrm{o} \mathrm{sol} \mathrm{nasceu,} \mathrm{às} 7 \mathrm{~h}$ tornou-se quente, às $7 \mathrm{~h} 30 \mathrm{os}$ bodes já foram para o pasto etc.” (THOMPSON, 1998, p.269). O valor relevante desses relatos é também entendido por Thompson de forma com que a história em si não possuí formas estáticas e repetitivas, cada sociedade, por mais "primitiva" que seja considerada, assimilou a contagem do tempo de uma maneira diferente, e é aí que está o desafio em estudá-las. Da mesma forma que os nuer e os nandi calculavam o tempo de 
sua maneira específica, Pierre Bourdieu relatou que os camponeses cabilas da Argélia tinham uma repulsa pelo relógio, que chamavam de "a oficina do diabo".

A conveniência de se compilar o entendimento do tempo que esses povos possuem tem cabimento quando acontece uma passagem que transformaria nossa relação com o relógio: o surgimento da mão-de-obra assalariada. Os casos mencionados anteriormente fazem sentido, e só poderiam ser dessa forma, pela formatação familiar e, principalmente, por se tratarem de organizações sociais isoladas, pois mesmo quando disserta sobre alguns pequenos artesões e/ou comerciantes, Thompson já relata que existe algum tipo de disciplina do trabalho, nem que seja entre o chefe de família e seus próprios filhos, isto é, a divisão de trabalho, somada com o a troca da mão-de-obra por algum dinheiro, já transforma a relação com o tempo:

Mesmo nesse caso, o tempo está começando a se transformar em dinheiro, o
dinheiro do empregador. Assim que se contrata a mão-de-obra real, é visível
a transformação da orientação pelas tarefas no trabalho de horário marcado. É
verdade que a regulação do tempo de trabalho pode ser feita independente de
qualquer relógio - e, na verdade, precede a difusão desse mecanismo. Ainda
assim, na metade do século XVII, os fazendeiros ricos calculavam as suas
expectativas de mão-de-obra contratada em "dias de trabalho"
(THOMPSON, 1998, p.272).

Com base nesses episódios e na já modificada relação com o tempo, o desenrolar da nossa história com o relógio começa a ganhar ares de cada vez mais racionalidade, essa fortemente atrelada ao ganho do dinheiro e à disciplina. Desde o surgimento do pêndulo e dos ponteiros dos minutos, os relógios foram se tornando artefatos indispensáveis para os trabalhadores e seus empregadores, dependendo dos dotes dos ferreiros que os construíam. Junto de todas essas especializações, a produção de relógios aumentou muito, assim como sua precisão, acarretando em alguns causos que Thompson traz como meio de ilustrar o ambiente de uma época - fim do século XVIII e início do século XIX -, como quando o contrabando de relógios começou a preocupar a "Companhia dos Relojoeiros", mas também ajudou para que os mais pobres conseguissem comprar o objeto, que normalmente era fabricado em ouro ou prata; ora quando se iniciou uma taxação em cima de cada relógio vendido, vinda do Ministro do Tesouro, que, vislumbrado pela expectativa de bons ganhos, causou um descontentamento tanto por parte dos relojoeiros quanto dos que consumiam os relógios, visto o alto preço que era cobrado, acabando, no fim das contas, em extinguir tal imposto, em decorrência da impossibilidade de contabilizar todos os relógios que estavam circulando.

Revista Em Debate (UFSC), Florianópolis, volume 17, p. 55-69, 2017. ISSNe 1980-3532 
Essa propagação do relógio em conjunto com a crescente industrialização da economia provocou uma "irregularidade" nos padrões de trabalho. É claro que do ponto de vista dos trabalhadores, antes preocupados somente com uma produção familiar, alternada, onde o ócio fazia parte da sua produtividade, era de se estranhar a nova rotina imposta pelas máquinas e, muito mais, por seus chefes que nunca haviam visto tanta possibilidade de ficarem mais ricos. Esse estranhamento é muito bem explorado em uma canção ${ }^{3}$ com impulsos melancólicos daquilo que os trabalhadores ingleses da Sheffield do século XVIII adoravam, chamada "Santa Segunda-Feira", sem dúvidas era uma menção de resistência aos novos padrões de trabalho impostos pelos donos das recém-chegadas máquinas, bem como uma exaltação de seus costumes e cultura:

Quando numa boa Santa Segunda-Feira,
Sentados à beira do fogo da forja,
Contando o que se fez no domingo,
Com alegria jovial conspiramos,
Logo escuto a porta do alçapão se erguer,
Na escada está minha mulher:
"Ao diabo, Jack, vou bater na tua cara,
Tu levas uma vida de bêbado irritante,
Ficas aí sentado em vez de trabalhar,
Com o cântaro sobre o joelho;
Maldito, tudo contigo é sorrateiro,
E eu a trabalhar para ti como uma escrava."

A "Santa Segunda-Feira" assume moldes de uma típica forma de resistência cultural às regras que estavam vindo com o capitalismo industrial. Vadiar na segundafeira se tornava santo pelo costume nutrido durante muitos anos pelos trabalhadores ingleses, em que Thompson retrata que esse hábito poderia ser visto mais ou menos de forma universal em "[...] todos os lugares que existiam indústrias de pequena escala, domésticas e fora da fábrica. Essa tradição era geralmente encontrada nos poços das minas, e às vezes continuava na manufatura e na indústria pesada.” (THOMPSON, 1998, p.283). O autor constatou que essa tradição se perpetuou até o século XX na Inglaterra, adquirindo a segunda-feira uma função de "reparar" os estragos causados por bebedeiras e outras festividades do final de semana. Além de ser uma tradição dos trabalhadores, a Santa Segunda-Feira pode ser entendida como uma afronta a cada vez mais rápida contagem do tempo, já que os donos tanto dos pequenos quanto dos grandes negócios não tinham a intenção de estender o descanso de seus empregados, e os

\footnotetext{
${ }^{3}$ Tal canção se chama The jovial cutlers, e mostrava uma faceta das muitas tensões domésticas entre os maridos e mulheres.
}

Revista Em Debate (UFSC), Florianópolis, volume 17, p. 55-69, 2017. ISSNe 1980-3532 
empregados, igualmente, de serem contrariados por terem que trabalhar na segundafeira.

\section{A peculiaridade dos ingleses}

A noção do lazer ganha um aspecto fundamental quando se aborda a peculiaridade dos ingleses no tocante de sua noção de tempo de trabalho em consoante com o avançar do capitalismo, mas antes de abordá-la é necessário, novamente, de mais uma alusão histórica dos fatos que desembocaram nessa criação capitalista, admitindo que antes da Revolução Industrial o lazer e/ou ócio não eram tomados como tal, assim como a contagem do tempo, ambos foram sendo manufaturados.

Foi na Inglaterra onde a industrialização teve seu berço e deu seus primeiros passos, contudo, os acontecimentos da Revolução Gloriosa foram os que realmente fizeram com que os ingleses experienciassem algo diferente da Revolução Francesa como é o exemplo mais utilizado para comparação - em correspondência às classes. Nessa esteira de grandes acontecimentos que fazem parte da queda de Carlos I, Thompson dialoga, em As peculiaridades dos ingleses, com aquilo que Perry Anderson e Tom Nairn ${ }^{4}$ estavam indicando como características distintas da Revolução Inglesa em comparação com a Francesa:

1) No caráter prematuro e incompleto da revolução do século XVII. Nos compromissos decorrentes de 1688 e 1832, a burguesia industrial não conseguiu obter hegemonia inconteste nem refazer as instituições dominantes da sociedade à sua própria imagem. [...] 2) Porque a revolução do século XVII foi "impura", e a luta conduzida em termos religiosos, a burguesia, além de nunca ter desenvolvido uma visão de mundo ou autoconhecimento coerente, satisfez-se com uma "ideologia" do "empirismo", que tem aparentemente caracterizado a cultura intelectual inglesa até os dias de hoje [...] 3) Uma revolução burguesa prematura deu origem a um movimento prematuro da classe trabalhadora, cujas heroicas lutas durante a Revolução Industrial foram anuladas pela ausência de crescimento teórico correspondente [...] (THOMPSON, 1978, p.80).

\footnotetext{
${ }^{4}$ Tanto Perry Anderson quanto Tom Nairn estavam na direção da revista New Left Review por volta de 1962. Thompson também fez parte do corpo editorial da New Left e ajudou a fundá-la. "Ainda em 1957, foi criada, por um grupo de estudantes de Oxford, a revista Universities and Left Review. Em dezembro de 1959, houve o lançamento do projeto de fusão das duas revistas, New Reasoner e Universities and Left Review, dando origem à New Left Review, a partir do início de 1960. Participavam do grupo muitos jovens intelectuais que, posteriormente, ganhariam notoriedade e destaque como Ralph Milliband, Raymond Williams, Peter Worsley, Doris Lessing, Raphael Samuel, Stuart Hall e Dorothy e Edward Thompson. Desde o início, o grupo majoritário da New Left Review sustentava que era imprescindível, para o desenvolvimento do socialismo na Grã-Bretanha, a mudança radical na consciência política do movimento operário inglês. " (MULLER \& MUNHOZ, 2010, p.4)
}

Revista Em Debate (UFSC), Florianópolis, volume 17, p. 55-69, 2017. ISSNe 1980-3532 
O aparente pessimismo com que a Revolução foi vista por Perry Anderson e Tom Nairn assume moldes claros se formos tentar entender a preocupação de Thompson com o papel da burguesia e em como a formação de uma classe trabalhadora que possivelmente não alcançou a "robustez" necessária para que sua agenda pudesse ser levada em conta com mais intensidade, no entanto, Thompson não concordava com a análise de seus colegas, onde arremata que essas três "características distintas" da Revolução (e tantas outras), esmiuçadas com mais cuidado, mostrariam outras peculiaridades diferentes das vistas pelos dois autores ${ }^{5}$. Em Patrícios e plebeus, a necessária vinculação entre a gentry e os "trabalhadores pobres" - nos termos do próprio Thompson - começa a ser vislumbrada. O autor discute, em um primeiro momento, se existiria no século XVIII um paternalismo presente na disputa entre as classes, o que ele debate também no sentido de que não seria um patriarcalismo, mas essa batalha conceitual será deixada de lado, uma vez que o interesse aqui está em desmistificar a real dinâmica entre os patrícios e plebeus. Dessa forma, nota-se que o que importava mesmo, antes do paternalismo entrar no jogo, era a relação com o dinheiro. A maioria dos cargos no Governo e na Igreja eram passíveis de serem comprados e vendidos, tendo a gentry sendo reconhecida mais pela quantidade de capital acumulado do que pelo seu sangue.

Direitos de uso, privilégios, liberdades, serviços - tudo podia ser traduzido num equivalente em dinheiro: votos, direitos de propriedade nos burgos, a imunidade dos cargos da paróquia ou do serviço das milícias, a liberdade dos burgos, os portões nas terras comunais. Este é o século em que o dinheiro "dá as cartas", em que as liberdade se tornam propriedades e os direitos de uso são reificados. (THOMPSON, 1998, pp.32-33).

O paternalismo que teoricamente existia entre patrícios e plebeus mais parecia o retrato de um passado distante, e mesmo sendo do passado, Thompson não concordava que havia essa preocupação paternal tão intensa comumente aceita por outros

\footnotetext{
${ }^{5}$ Segue uma passagem de uma das considerações de Thompson em relação a Anderson e Nairn: "O tema da argumentação de nosso autores é: a tragédia da nossa história foi o fato de o marxismo ter passado em branco pela classe trabalhadora britânica. A culpa é colocada sobre a insularidade e o conservadorismo sociológico dos sindicatos britânicos e sobre a omissão dos intelectuais britânicos. Um modelo simples de objetividade-subjetividade é empregado. Por meio dele, os sindicalistas são vistos como cegos, práxis instintiva, e os intelectuais, como a encarnação de uma consciência política articulada. [...] Se, no entanto, inserirmos este modelo em um contexto político particular, ele não funciona tão bem assim. Em qualquer momento entre 1890 e os dias de hoje, encontramos uma tradição minoritária muito substantiva, associada à esquerda organizada, influenciando alguns dos principais sindicatos. Encontraremos uma sistemática formação marxista de base - SDF, Nclc, Partido Comunista - [...] Nem um desses grupos vagamente definidos ajusta-se à caracterização de Anderson do fabianismo [...]" (THOMPSON, 1998, p.133-134).
}

Revista Em Debate (UFSC), Florianópolis, volume 17, p. 55-69, 2017. ISSNe 1980-3532 
historiadores, na visão dele existia uma espécie paternalismo antes da industrialização e mesmo em cantões, aldeias, pequenos burgos, enfim, algumas localidades -, onde a classe trabalhadora não tinha consciência de sua existência, melhor dizendo, não existia classe trabalhadora, no entanto, uma filiação entre um mestre e seus aprendizes poderia ser paternal pelas vantagens obtidas a ambos em adotar esse modelo, mas não se configurava como aquele sentimento idealizado de que ambos constituiriam uma relação social fraternal.

Nesse sentido, Thompson logo se afasta da "tentação" de ir mais a fundo no assunto do paternalismo, concentrando suas forças em destrinchar o que acontecia no século XVIII entre gentry e trabalhadores, questionando a erosão das formas "semilivres" de trabalho. O fato é que a transição de um estilo de trabalhador que antes da industrialização tinha algumas garantias (mesmo que "paternais"): morava no próprio lugar onde trabalhava a maioria das vezes, detinha de tradições fortemente amparadas por várias gerações etc.; para um trabalhador "livre", assalariado, que poderia transitar de um ofício para o outro, não foi algo bem recebido e muito menos pacífico. Thompson lembra que os senhores, a partir da vinda dessa nova modalidade de trabalho, não queriam mudar sua vinculação de antes da industrialização, eles queriam aproveitar do melhor dos "dois mundos", tratando os trabalhadores com salários menores - graças à concorrência - e ao mesmo tempo condicionando-os em expedientes de servidão.

Os "novos" trabalhadores, cada vez mais absorvendo as mudanças sociais e econômicas, eram indisciplinados, faltavam ao trabalho, não cumpriam com os combinados, brigavam com o relógio e desrespeitavam as novas regras impostas por seus chefes e pela sociedade inglesa pós-Revolução Gloriosa. "Se os poderosos ficavam tão afastados dos olhos públicos, dentro de seus parques e mansões, também os plebeus, em muitas de suas atividades, ficavam afastados deles. O domínio paternal efetivo não só requer autoridade temporal, mas também autoridade espiritual e psíquica" (THOMPSON, 1998, p.50).

Os patrícios precisavam dos plebeus para trabalhar em seus negócios e os plebeus precisavam dos empregos e da mínima segurança oferecida pelos patrícios em seus empregos. A relação entre essas duas classes era simbiótica no fim das contas, tanto por meio do teatro que era praticado pelos patrícios e que resultava em generosidades direcionadas aos pobres quanto nas diversas vezes que plebeus desfrutavam de suas festanças - causadoras de faltas no trabalho e outros problemas - 
em que patrícios poderiam interferir e não o faziam. A sociedade inglesa do século XVIII não era a sociedade de "uma só classe", como alguns defendiam, pois existiam governantes e governados, muito ricos e muito pobres, isto é, as classes estavam ali, mas a consciência de sua existência, principalmente nos trabalhadores, talvez ainda não estivesse tão explícita.

\footnotetext{
Mas a presença política da plebe, "turba" ou "multidão" é manifesta. Ela colidiu com a alta política em várias ocasiões críticas - os tumultos de Sacheverell, a agitação do imposto de consumo, o imposto da cidra, as ebulições patrióticas e chauvinistas que apoiaram a carreira do Pitt mais velho, mais tarde Wilkes e os motins de Gordon, e ainda mais além. Mesmo quando a besta parecia estar adormecida, as sensibilidades irritáveis de uma multidão libertária definiam, no mais amplo sentido, os limites do que era politicamente possível. (THOMPSON, 1998, p.57).
}

Após essa breve explanação de alguns pontos importantes entre a relação das classes presentes na Inglaterra que Thompson está analisando - onde não será investigado com mais minucia as questões teóricas envolvendo tais atributos presentes nessas disputas, como a importância do conceito de consciência de classe ou mesmo da intensa discussão se haveria uma só classe, devido às limitações desse ensaio - volta-se ao tema geral da invenção do tempo, aplicando-se agora na função do lazer para os trabalhadores ingleses.

O avanço da industrialização não só diversificou as formas de trabalho, como também transformou a cidade enquanto espaço urbano. Com mais pessoas morando em um mesmo espaço, exemplarmente nas cidades, o comércio foi alterado, as formas de sociabilidade sofreram mutações, em suma, o lazer não se restringia mais às "Santas Segundas-Feiras". Aquela fração de tempo onde os trabalhadores aproveitavam seu ócio não era mais a mesma daquele passado não tão distante, assim como os ricos de igual forma remodelaram suas maneiras de usufruir do lazer, transformando-o em um imenso teatro, no lugar em que se mostravam uns para os outros, com seus objetos de luxo, regados a uma teatralidade que tinha a função de diferenciá-los do "povo". Os novos modelos de consumo advindos com a agora sociedade capitalista-industrial reforçavam a diferença entre classes, principalmente vindo de cima para baixo, tendo o status social mais importância do que qualquer outra qualidade, mesmo que seja intensamente ensaiado, fazendo parte daquele teatro maior característico da gentry inglesa.

Os pobres, que Thompson comenta que não viam como irmãos daqueles poucos ricos, desfrutavam de seu "tempo-livre" nos bailes, feiras, festivais, que eram esperados com muita necessidade, pois consistiam naqueles momentos de desenvoltura, de Revista Em Debate (UFSC), Florianópolis, volume 17, p. 55-69, 2017. ISSNe 1980-3532 
esquecer os dias de trabalho intensos, de seus patrões e da vida difícil que levavam. No século XVIII, Thompson anota que houve um aumento na "libertinagem" conferida ao lazer: as pessoas bebiam mais, ficavam mais tempo em casa do que no trabalho, graças aos grandes feriados que não mais seguiam o calendário da Igreja etc. Os patrícios, ao se depararem com o jeito com o qual seus trabalhadores estavam aproveitando de seu lazer, muitas vezes apoiavam tais festanças e igualmente não se intrometiam, a não ser que a situação estivesse próxima de fugir do controle, como quando notavam alguma espécie de mobilização organizada em protestos e/ou em algumas dessas comemorações, obviamente indo contra seus interesses.

Quando o humor dos pobres explodia em rebeliões, os ricos senhores intervinham como podiam, contudo, o interessante é notar que mesmo a Inglaterra estando na vanguarda do capitalismo industrial, a peculiaridade dos ingleses não estava somente localizada nisso, já que tudo que veio após esse período de consolidação da indústria estabelecia-se em experiências novas para todos os seus participantes. $\mathrm{O}$ século XVIII semeou na classe trabalhadora inglesa - em seus mais diversos ofícios: artesões, mineiros, fazendeiros, donos de pequenas lavouras, ferreiros etc. - uma vivência em um novo sistema econômico que possibilitaria, já pelo início do século XIX, a formação da primeira classe operária, organizada em manifestações contra seus patrões; em ataques contra a aristocracia; participando de barganhas políticas para defenderem seus interesses.

\footnotetext{
Thompson desenvolveu a tese de que as elites exerciam o controle e a dominação das plebes por meio da hegemonia cultural. Para o autor, naquele contexto, as plebes empregavam práticas defensivas alicerçadas em tradições fundadas no direito consuetudinário. Dessa forma, buscavam impor à gentry obrigações definidas pelos costumes. Ao estudar a resistência popular na Inglaterra ao longo do século XVIII, Thompson descortina a existência de uma complexa trama fundada em reciprocidades paternalistas por intermédio da qual a gentry exercia o controle e a subordinação das plebes. Todavia, para ele, esse processo não pressupunha a ausência de conflito, mas a sua delimitação dentro de parâmetros aceitáveis para as elites inglesas. Dessa forma a hegemonia da gentry poderia conter revoluções, mas não contestações ou rebeliões. (MULLER \& MUNHOZ, 2010, pp.10-11).
}

Com a passagem do século XVIII para o século XIX, que contaram com uma diversidade de acontecimentos, i.e. Revolução Francesa, a disciplina presente na sociedade inglesa já enraizada pelo capitalismo industrial foi reforçada. Se com o salto de uma produção doméstica para uma economia de produção em escala muito maior já modificou o controle do tempo na sociedade, agora com o processo mais bem-acabado, 
com outras Revoluções acontecendo, absorve um destaque maior a ampliação do domínio moral da Igreja Católica, restringindo ainda mais o lazer dos pobres. Durante o século XVIII já havia uma disputa entre ditames da Igreja em confronto com aquilo praticado pelos trabalhadores em seu tempo de lazer, todavia, a burguesia industrial ainda relevava esses ocorridos, porém, a chegada dos ideais da Revolução Francesa em solo inglês provocou uma sensação de tormento entre as classes mais ricas. A classe trabalhadora inglesa poderia se irromper inflada por seus companheiros franceses, mas isso não poderia acontecer, e aí é que a Igreja aparece como protagonista. Não só a Igreja, como visto, ajudou a regular e disciplinar ainda mais a vida dos indivíduos, também as autoridades policias reprimiram com mais intensidade.

As pressões favoráveis ao aumento da disciplina e da ordem partiam das fábricas, da religião e das autoridades, isto é, o trabalhador estava sendo obrigado de todos os lados a se adequar a uma realidade forjada para o mantimento de um sistema econômico estranho ao seu costume. O que os ricos não esperavam é que, com mais repressão, mais a classe trabalhadora foi se organizando, lutando por melhorias no trabalho, sendo algumas conquistas marcos no processo de relação entre empregadores e empregados, tais como as férias e a regulação da jornada de trabalho.

Por fim, o lazer dos trabalhadores continuou sendo regrado; o relógio continuou sendo o objeto que mais causava discórdias; o enfrentamento entre costumes e culturas transformou toda uma sociedade, bem como criou a primeira classe trabalhadora do mundo industrial, que mesmo com as inúmeras críticas recebidas a partir de sua conduta - inclusive de Thompson - não deixou de ser a primeira reunião de trabalhadores que tiveram a coragem de irem contra quem tinha muito mais poder, seja ele econômico, jurídico, policial ou qualquer outro. As manifestações, rebeliões, mortes, lutas e tudo o mais que a classe trabalhadora inglesa experimentou influenciou toda uma construção de classe que veio após ela. A visão de Thompson sobre a criação do tempo vai ao encontro do capitalismo industrial, pois sem ele não seria necessário que contássemos ou mesmo regulássemos os segundos, minutos e horas, já fazíamos isso sem o relógio, sem as fábricas, sem o a distinção entre lazer, trabalho e vida, no entanto, também não podemos nos prender em saudosismos do passado. Thompson entende que o capitalismo também causou coisas gratificantes, como a própria formulação da consciência de classe, induzida pela práxis dos trabalhadores em suas vidas, o que poderia ter sido diferente se talvez se superasse tal modelo que foi se constituindo, e não 
somente o enfrentamento por melhores escolhas dentro do sistema, mas isso não acredito ser necessário discutir, pois talvez estaríamos patinando sem sair do lugar, perdidos em teorias que pudessem ser formuladas e não foram, ou, como conta a história, se Roma tivesse perdido as guerras púnicas para Cartago, provavelmente nossos livros exaustariam os cartagineses, a história sempre foi contada pelos vencedores. Thompson enfrenta essa tese com muito louvor.

\section{Considerações finais}

$\mathrm{O}$ intuito principal desse ensaio foi o de construir um apanhado daquilo que Edward P. Thompson escreveu sobre a "invenção do tempo" no capitalismo industrial ascendente da Inglaterra. A quantidade de obras que o autor disponibiliza que versam sobre o assunto é grande, sofisticada, repleta de argumentações com um cunho autoral muito forte, característico de um historiador marxiano dos bons. Inventamos o tempo porque somente utilizávamos de meios para conta-lo com vieses de uma organização primitiva; sua invenção foi necessária pelo desenvolvimento de um sistema econômico baseado no acúmulo de capital, no expansionismo no lucro, na diversificação da mãode-obra, na explosão demográfica das cidades que acomodavam as grandes empresas etc., poderia ser citado mais uma infinidade de resultados do capitalismo, mas o relógio foi singular por alguns motivos já demonstrados.

O trabalhador inglês, principalmente dos séculos XVIII e XIX - que é o espaço de tempo que Thompson mais se concentra quando fala desse tópico do tempo - foi o primeiro a ter a "oportunidade" de ser disciplinado pelo modo com que produzia seus bens. Os trabalhadores e as trabalhadoras tiveram uma mudança drástica em suas vidas quando a industrialização estava precisando de massas e mais massas para operarem as máquinas. Seus costumes, tradições e cultura foram reprimidos pelas mais diversas autoridades, seja a Igreja, o Rei, seus chefes, a polícia, em síntese, ser um trabalhador assalariado nada se parecia com a economia doméstica de antes, onde cada um tinha uma flexibilidade no seu trabalho que refletia na vida social. Thompson coteja uma infinidade de aspectos que foram sendo desenvolvidos para que o capitalismo industrial prosperasse, levando a Inglaterra para o topo dos países que mais acumulavam riquezas, só que essa postura refletiu também em seu povo. 
A classe trabalhadora foi se configurando a partir de diferenças que, antes dos estágios mais agressivos que o capitalismo foi alcançando, não eram tão imponente assim - isso em relação à burguesia e a aristocracia -, fazendo parte de mesma dinâmica de necessidade para a existência delas mesmas. O tempo foi sendo manipulado não somente com a colocação de grandes relógios nas Igrejas ou com seu modelo portátil nos bolsos dos trabalhadores; ele se transformou rapidamente e em consequência da disciplina necessária para se trabalhar nas novas fábricas, no mesmo momento que os ingleses foram geniais quando multiplicaram sua produção com a invenção da indústria, as consequências dessa inovação provocaram vários resultados que não puderam mais serem controlados, que se infiltraram no modo de vida que era levado principalmente pelos trabalhadores, obrigando-os a se adequarem ao modo de produção do capitalismo.

Aquilo que Thompson aborda essencialmente em Costumes em comum vai ao encontro de demonstrar que, apesar de sofrerem com o progresso do capitalismo, a classe trabalhadora inglesa, peculiar por ser a primeira, não foi submissa e menos ainda pouco combativa. Os trabalhadores se organizaram, praticaram ações muitas vezes não pensadas ou que davam a impressão para tal, mas nunca houve a sociedade de "uma só classe". A formação da consciência de classe para Thompson é clara: depende da experiência do dia-a-dia, das lutas enfrentadas pelo reconhecimento de sua cultura. Abordar a invenção do tempo não pode ser afastado totalmente do nascimento da luta de classes.

Por conseguinte, esse ensaio tentou adotar uma maneira mais "livre" de estudar o legado de Thompson. O tempo é uma parte importante de sua reflexão acerca da formação da classe trabalhadora inglesa, e o esforço foi de conversar com o autor nos pontos mais nodais de sua discussão e, quando necessário, ir mais a fundo em matérias que mereciam mais destaque. A conclusão que se chega - se é que a história nos deixa finalizar alguma coisa por completo - é a de que o lazer, o trabalho e a disciplina, tomados como os componentes mais básicos da vida de um trabalhador, sofreram mutações em decorrência do capitalismo, mas por mais óbvia que seja essa constatação, a peculiaridade que ocorreu na Inglaterra foi crucial para que esse sistema se tornasse hegemônico, e não só em questões de como lidar com o mercado e a produção, como também em como a cultura, o ócio, os espaços urbanos, a noção de Estado, política, etc. foram totalmente transfiguradas. 


\section{Referências}

MULLER, R.; MUNHOZ, S. Edward Palmer Thompson In: LOPES, Marco Antonio e MUNHOZ, Sidnei (orgs.).Historiadores Do nosso tempo S. Paulo: Alameda 2010, p. $31-52$.

THOMPSON, E. P. Costumes em Comum. S. Paulo: Cia. das Letras, 1998.

A Miséria da Teoria e outros Ensaios. Nova York: Montlhy Review Press, 1978 (tradução de Alexandre Fortes e Antonio Luigi Negro). 